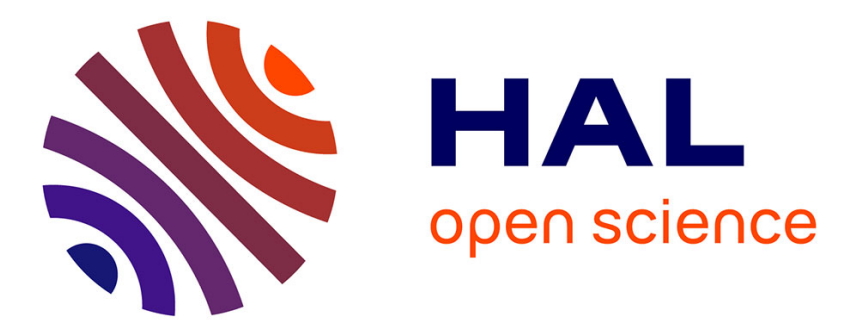

\title{
Hidden surface dynamical modes and SSH retrievals from a joint analysis of altimetry and microwave SST
}

Pierre Tandeo, Ronan Fablet, Pierre Ailliot

\section{To cite this version:}

Pierre Tandeo, Ronan Fablet, Pierre Ailliot. Hidden surface dynamical modes and SSH retrievals from a joint analysis of altimetry and microwave SST. IGARSS 20104: IEEE International Geoscience and Remote Sensing Symposium, Jul 2014, Quebec, Canada. pp.5123 - 5125, 10.1109/IGARSS.2014.6947650 . hal-01188830

\section{HAL Id: hal-01188830 \\ https://hal.science/hal-01188830}

Submitted on 31 Aug 2015

HAL is a multi-disciplinary open access archive for the deposit and dissemination of scientific research documents, whether they are published or not. The documents may come from teaching and research institutions in France or abroad, or from public or private research centers.
L'archive ouverte pluridisciplinaire HAL, est destinée au dépôt et à la diffusion de documents scientifiques de niveau recherche, publiés ou non, émanant des établissements d'enseignement et de recherche français ou étrangers, des laboratoires publics ou privés. 


\section{HIDDEN SURFACE DYNAMICAL MODES AND SSH RETRIEVALS FROM A JOINT ANALYSIS OF ALTIMETRY AND MICROWAVE SST}

\author{
Pierre Tandeo, Ronan Fablet* \\ Institut Mines-Télécom ; Télécom Bretagne \\ UMR CNRS 3192 Lab-STICC \\ Brest, France
}

\author{
Pierre Ailliot \\ University of Brest \\ UMR CNRS 6205 LMBA \\ Brest, France
}

\section{INTRODUCTION}

The availability of daily satellite Sea Surface Temperature (SST) data and theoretical results (see e.g., [1]) advocate for new methods to retrieve the Sea Surface Height (SSH) and the surface geostrophic currents from SST observations. The underlying hypothesis comes to assume that the local variations of the SST relate to the surface currents. Ocean turbulence models, such as the Surface Quasi Geostrophic (SQG) theory (cf. [2], [3]) or statistical methods like neural networks (cf. [4]) or latent class regressions (cf. [5]) provide different means to state the SST-SSH relationships. This later approach has the advantage to be completely parametric and to account for different transfer functions between SST and SSH. It relies on a conditional setting with respect to a hidden variable related to different dynamical modes at the surface of the ocean. In this paper, we aim at further developing such latent models with an emphasis on two aspects: (i) the modeling and learning of the spatio-temporal dynamics of the hidden dynamical modes using Markovian priors, (ii) the reconstruction of daily SSH fields from a joint analysis of microwave SST and altimetry observation series. We evaluate the proposed model both qualitatively and quantitatively with respect to the reference altimetry product.

\section{REMOTE SENSING DATA}

In this work, we achieve a joint analysis of microwave SST and altimetry. As altimetric data, we use the daily time Maps of Absolute Dynamic Topography (MADT) produced by Collecte Localisation Satellites (CLS) available online at http://www.aviso.oceanobs.com/. The considered SST data is the daily optimally interpolated microwave SSTs provided by Remote Sensing System (RSS) available online at http://www.ssmi.com/. The two data sources are interpolated at the same spatial resolution, i/e. $1 / 4^{\circ}$. Whereas the daily SST series actually involve daily satellite measurements, the daily MADT maps roughly refer to a weekly temporal resolution, as narrow-swath altimetry sensors involve a weekly

\footnotetext{
*Thanks to AVISO and RSS projects for providing data.
}

revisit time. The considered study area is the Agulhas current for the year 2004.

\section{PROPOSED APPROACH}

This section first describes the considered latent model for the identification and characterization of the hidden dynamical modes. In a second step, we focus on the two specific objectives of this study.

The considered model relates the local SSH variability to the SST field in a neighboring region. For a given spatiotemporal location $(s, t), \mathbf{Y}(s, t)$ encodes the local SSH variability through a 3-dimensional vector formed by the $\mathrm{SSH}$ value and the surface current $(\mathrm{U}, \mathrm{V})$ and $\mathbf{X}(s, t)$ is the vectorized version of the local SST patch ( $p$-dimensional vector) centered in $s$ at time $t$ (cf. Fig. 1(a)). Assuming that different dynamical modes may be exhibited, we denote by $Z(s, t)$ the latent variable corresponding to the hidden dynamical mode at ocean surface in play at location $s$ and time $t$. We assume that the conditional probability of $\mathbf{Y}$ given $\mathbf{X}$ and $Z=k$ is given by

$$
p(\mathbf{Y} \mid \mathbf{X}, Z=k) \propto \mathcal{N}_{k}\left(\mathbf{Y} ; \mathbf{X} \boldsymbol{\beta}_{k}, \boldsymbol{\Sigma}_{k}\right)
$$

where $\mathcal{N}_{k}$ represents a multivariate Gaussian probability density function evaluated in $\mathbf{Y}$ with mean $\mathbf{X} \boldsymbol{\beta}_{k}$ and covariance $\boldsymbol{\Sigma}_{k}$. The inference of model parameters (i.e. the statistical parameters given in Eq. (1) and the number of modes $K$ ) involves classical Bayesian inference techniques (cf. [5]). In the considered study region, we identify $K=4$ hidden dynamical modes, corresponding to 4 different slopes and covariances in the regression between $\mathbf{X}$ and $\mathbf{Y}$ (cf. Fig. 1(b)). We also show that the dynamical modes correspond to geostrophic or advective displacements with different amplitudes (cf. [5] for more details).

In operational situations, following Eq. (1), the SSH and surface currents can be predicted conditionally to the SST field and the hidden dynamical mode. In practice, the microwave SSTs are always available, even in cloudy conditions, and the SST observation is available daily. As mentioned above, the intrinsic altimery time resolution is 


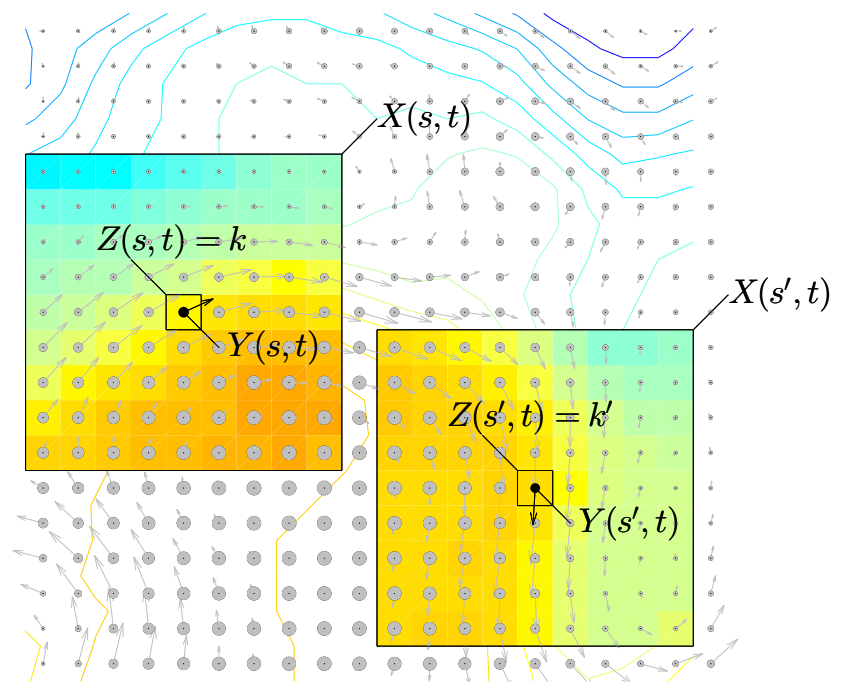

(a)
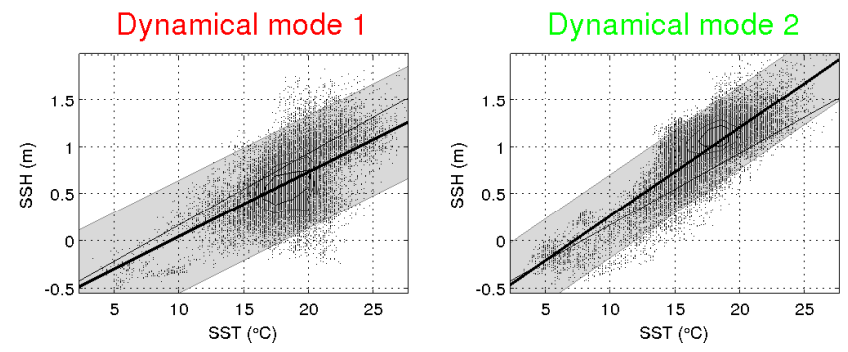

Dynamical mode 3
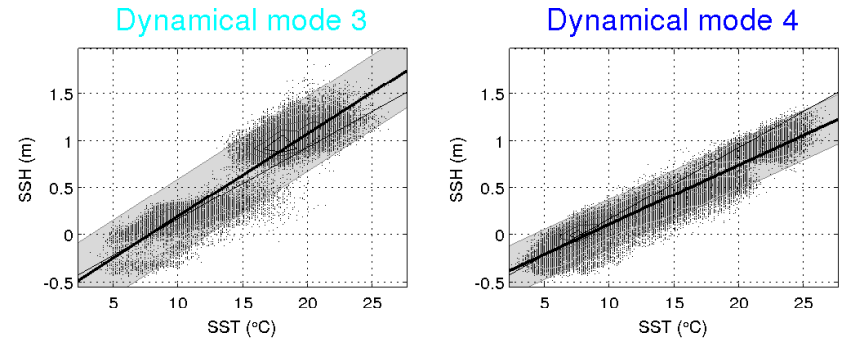

(b)

Fig. 1. (a) Sketch of SST patches (in degree represented in false colours), noted $\mathbf{X}$, and the corresponding SSHs (in meter represented by dots) and surface currents (in meter per second represented by quivers) noted $\mathbf{Y}$ at the central location $s$ and $s^{\prime}$ at time $t$. (b) SSH as a function of SST in the Agulhas current. For each dynamical mode $Z$, we give the regression line and the $95 \%$ confidence envelope. The fine black line is a benchmark curve corresponding to the global linear regression (with a one-mode model).

rather weekly. To overcome the lack of collocations between daily SST and SSH observations, we address the inference of the dynamical modes at a daily resolution using Markovian priors. More precisely, at each location $s$, we use a Hidden Markov Model (HMM). We estimate the stationary law and the transition matrices using an Expectation-Maximization procedure (cf. [6]). Then, the posterior likelihoods of the hidden dynamical modes are evaluated from a forward-backward algorithm (cf. [7]). Given these posterior likelihoods and the daily SST local variations $\mathbf{X}$, we apply Eq. (1) to reconstruct the SSH and surface geostrophic currents at a daily resolution. The scheme of the corresponding model is given in Fig. 2.

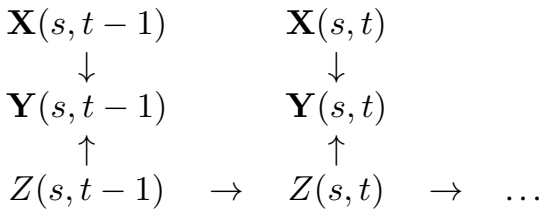

Fig. 2. Directed acyclic graph of the proposed model. At a specific location $s$, we use a hidden Markov chain to model the temporal evolution of the dynamical mode $Z$. Then, we estimate the SSH and surface current $(\mathbf{Y})$ conditionally to the local SST variations $(\mathbf{X})$ and the dynamical mode. The delay between two consecutive times is one day.

\section{RESULTS}

Using the joint time series of SST and SSH, we are able to spatially and temporally track the hidden dynamical modes at the surface of the ocean (cf. Fig. 3). The first results of the hidden Markov model indicate a large variability in the estimations of the stationary laws and transition matrices. For instance, at locations situated in the main Agulhas current ( $Z=1$ in Fig. 3(a)), the transitions to the others dynamical modes is unlikely. By contrast, in the return Agulhas current moving from $36^{\circ} \mathrm{S}$ to $44^{\circ} \mathrm{S}$ along the year, the switching probabilities between $Z=1,2,3$ are significant. Such an example is given in Fig. 3(b).

Then, knowing the temporal dynamics of $Z$ and the SST local variations, we reconstruct the SSH at each location $s$ for the year 2004. The results are very closed to the MADT estimations, except in the Agulhas retroflection region where the surface dynamics is more advective than geostropic (cf. Fig. 4(a)). Moreover, the estimations differ during the austral summer, when the occurrence of the advective modes are more likely (cf. Fig. 4(b)). In the first results, we also remark a benefit to use the SST data to retrieve the warm core rings in the Agulhas current. Indeed, the MADT product only uses very sparse altimetric data and may not be able to spatially and temporally track these structures.

\section{REFERENCES}

[1] G. Lapeyre and P. Klein, "Dynamics of the upper oceanic layers in terms of surface quasigeostrophy theory," Jour- 


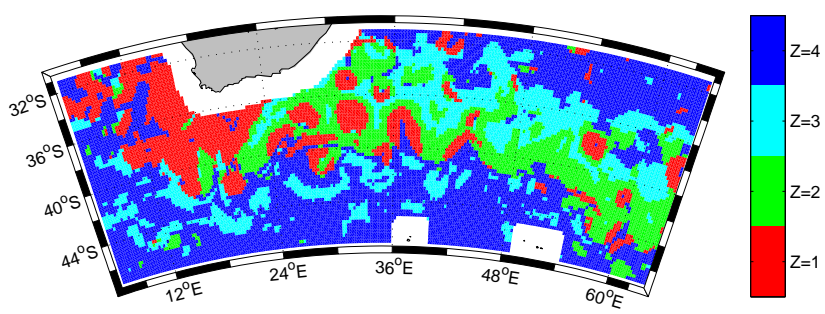

(a)

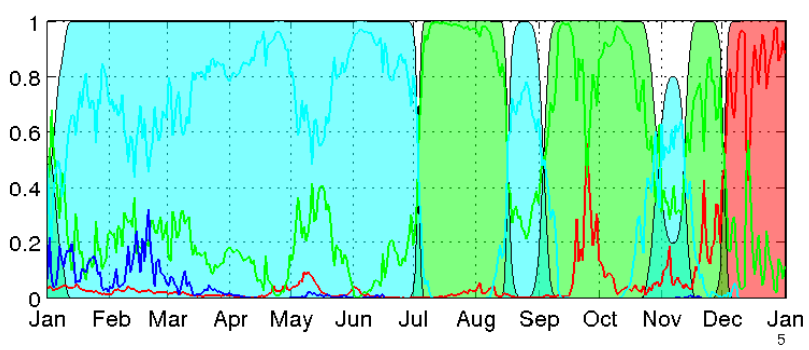

(b)

Fig. 3. (a) Spatial distribution of the $K=4$ dynamical modes for a given date. (b) Time series of the observed (lines) and filtered (filled areas) posterior likelihoods for each dynamical mode at location $36^{\circ} \mathrm{S}, 36^{\circ} \mathrm{E}$.

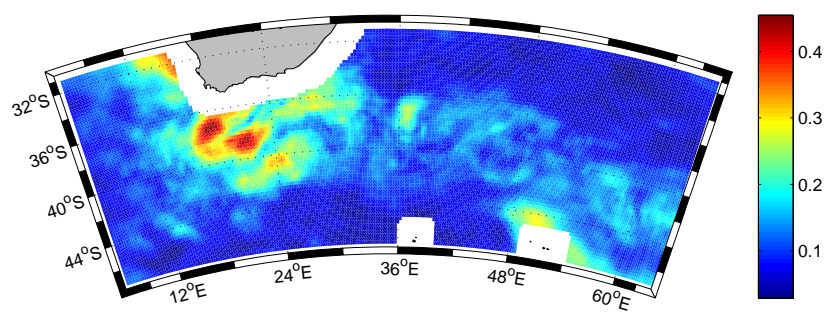

(a)

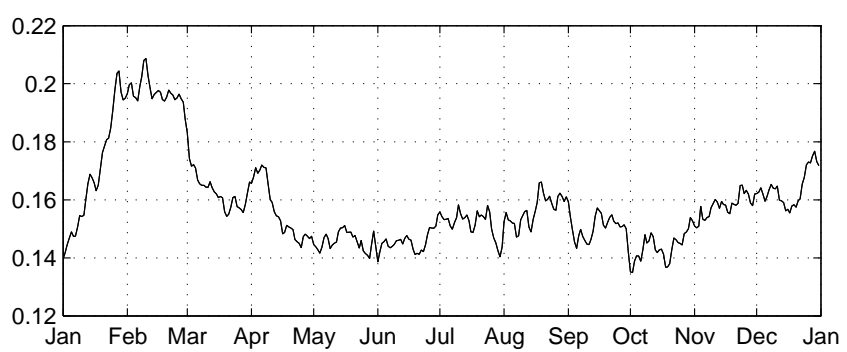

(b)

Fig. 4. Difference in space (a) and time (b) between the estimated SSH using model given in Fig. 2 and the reference SSH (coming from the MADT) along the year 2004. nal of Physical Oceanography, vol. 36, no. 2, pp. 165176, 2006.

[2] J. Isern-Fontanet, G. Lapeyre, P. Klein, B. Chapron, and M.W. Hecht, "Three-dimensional reconstruction of oceanic mesoscale currents from surface information," Journal of Geophysical Research, vol. 113, no. C9, pp. C09005, 2008.

[3] C. González-Haro and J. Isern-Fontanet, "Ocean surface currents reconstruction at a global scale from microwave measurements," in Geoscience and Remote Sensing Symposium (IGARSS), 2012 IEEE International. IEEE, 2012, pp. 3780-3783.

[4] M. Jouini, M. Lévy, M. Crépon, and S. Thiria, "Reconstruction of satellite chlorophyll images under heavy cloud coverage using a neural classification method," $R e$ mote Sensing of Environment, vol. 131, pp. 232-246, 2013.

[5] P. Tandeo, B. Chapron, S. Ba, E. Autret, and R. Fablet, "Segmentation of mesoscale ocean surface dynamics using satellite sst and ssh observations," Geoscience and Remote Sensing, IEEE Transactions on, vol. PP, no. 99, pp. 1-9, 2013.

[6] A.P. Dempster, N.M. Laird, and D.B. Rubin, "Maximum likelihood from incomplete data via the em algorithm," Journal of the Royal Statistical Society. Series B (Methodological), pp. 1-38, 1977.

[7] L.E. Baum, T. Petrie, G. Soules, and N. Weiss, "A maximization technique occurring in the statistical analysis of probabilistic functions of markov chains," The annals of mathematical statistics, vol. 41, no. 1, pp. 164-171, 1970. 